\title{
Mediterranean diet and metabolic syndrome: a cross-sectional study in the Canary Islands
}

\author{
EE Álvarez León ${ }^{1, *}$, P Henríquez ${ }^{2}$ and L Serra-Majem ${ }^{3}$
}

${ }^{1}$ Servicio de Medicina Preventiva del Complejo Hospitalario Materno-Insular de Gran Canaria: ${ }^{2}$ Departamento de Enfermería. Universidad de Las Palmas de Gran Canaria: ${ }^{3}$ Departamento de Ciencias Clínicas. Universidad de Las Palmas de Gran Canaria

Submitted 18 April 2006: Accepted 14 November 2006

\begin{abstract}
Objective: Assessment of relation between metabolic syndrome (MS) and Mediterranean diet (MD) adherence.

Design: Cross-sectional study. ATP III definition of MS was used. Adherence to MD was assessed with a Food Frequency Questionnaire. Intakes of cereal, fruit, legumes, vegetables, fish, nuts, monounsaturated to saturated ratio, alcohol from red wine, whole-fat dairy products and red meat were considered.

Setting: Representative sample of population from the Canary Islands (Spain) participating in the Canarian Nutrition Survey (ENCA).

Subjects: 578 adults $>18$ years.

Results: Of the subjects, $24.4 \%$ presented MS. Once adjusted, MD adherence was not related to MS prevalence, but subjects in the third tertile of adherence presented $70 \%$ lower prevalence of the blood pressure criteria and 2.5 times more prevalence of the glycaemia criteria with respect to the first tertile. Red meat intake was associated with higher prevalence of blood pressure criteria. Moderate alcohol intake from red wine was associated with lower prevalence of these criteria in women and lower prevalence of HDL cholesterol criteria in men. Fruit intake showed a protective effect on triglyceride criteria, whereas vegetable intake was associated with higher prevalence of this criterion. Cereals' intake showed a protective effect over insulin resistance measured by high insulinaemia level. Fruit intake showed a significative protective effect over high Homeostasis Model Assessment index. Whole-fat dairy products showed a significant protective effect on the glycaemia criteria. High monounsaturated to saturated fatty acid intake showed a protective effect on insulin resistance.

Conclusions: Some components of the MD showed a protective effect on the MS and its components.
\end{abstract}

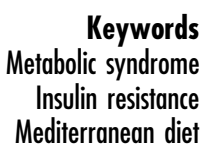

\section{Introduction}

Cardiovascular diseases are the first death cause in European countries $^{1}$. It is well known that hypercholesterolaemia, hypertension, tobacco consumption and other factors increase the risk of developing cardiovascular disease $^{2}$. In Spain, a 'Spanish paradox' has been described $^{3}$, consisting of a high prevalence of cardiovascular risk factors but low incidence and mortality for ischaemic heart disease ${ }^{4}$. The existence of protective factors in Spanish subjects was considered to be a possible explanation of this paradox. One of the proposed protective factors was a dietary pattern close to the Mediterranean diet (MD). In the Canary Islands, as opposed as to what is found in the rest of Spain, a high prevalence of cardiovascular risk factors coexists with one of the highest cardiovascular mortality rates of the country $^{5}$. The present paper is intended to clarify some issues concerning dietary habits of the Canarian population that could influence on their cardiovascular morbidity and mortality.

The metabolic syndrome (MS) is a cluster of cardiovascular risk factors ${ }^{2}$ that could affect one of every four Spaniards $^{6}$. The ATP III establishes that a subject has MS when he/she fulfils more than or equal to three of the five following criteria: high blood pressure (or medical treatment for hypertension), impaired fasting glycaemia (or medical treatment for diabetes), hypertriglyceridaemia, low HDL cholesterol levels and abdominal obesity.

Insulin resistance has been linked to MS development ${ }^{7}$. It must be pointed out that there is no scientific consensus as to how to diagnose an insulin-resistance state. 
Nevertheless, for the purposes of this work the HOMA (Homeostasis Model Assessment) model has been chosen. The HOMA is an index that relates fasting insulin and glucose levels ${ }^{8}$. There is no standardised threshold to determine when a subject has insulin resistance. In Spain, Ascaso et al. ${ }^{9}$ have established a threshold based on the percentile 90 of fasting insulinaemia and the same percentile of HOMA index, of a control population (subjects without clinical or analytical parameters of insulin resistance).

Early diagnosis of MS and a preventive approach could diminish cardiovascular disease. A healthier lifestyle, with moderate physical activity and adequate nutritional habits, were the initial steps to prevent MS and cardiovascular complications $^{2}$. In spite of its high prevalence and importance, there is no agreement about the dietary factors that may attenuate or promote it.

There is some evidence of the beneficial role of the MD on MS. In a randomised controlled study carried out in Naples (Italy) ${ }^{10}$ with 180 MS patients, it was observed that in the intervention group (following a Mediterranean-style diet), the prevalence of MS was reduced by $55.6 \%$, as compared with a reduction of $13.3 \%$ in the control group (following a prudent diet) in a 2 -year period. In another randomised controlled study carried out in Germany ${ }^{11}$ with 101 patients with established coronary artery disease, an MD approach could not change metabolic risk factors in a 1-year period. Nevertheless, it must be pointed out that the nutritional intervention developed in the German study was far from being a real MD pattern in some aspects (high intake of red meat and meat products, low use of olive oil, etc.).

The definition of 'MD' is not easy' ${ }^{12}$. It could be considered as a food pattern that characterises a way of life and a culture, and that could improve health and quality of life of those subjects following $\mathrm{it}^{13}$. Some food components of the MD could be: high intake of vegetables, legumes, fruit, nuts and cereal (mostly whole grain); high to moderate intake of fish; low intake of saturated fatty acids but high intake of unsaturated fatty acids (specially olive oil); moderate to low intake of dairy products (specially cheese and yoghurt); low intake of red meat and moderate intake of alcohol (mostly red wine) ${ }^{14}$.

In epidemiological studies assessing the relation of the MD and the health parameters, indexes of adherence to a previously established MD food pattern were used $^{12}$. The indexes were based on a single score that results from the combination of measured intakes of the different individual components of the MD food pattern.

The present work analysed the relationship between the individual index of adherence to a pre-established MD score, and the prevalence of MS, its criteria and insulin resistance, in a representative sample of a Spanish population.

\section{Material and methods}

\section{Subjects}

In the Canarian Nutrition Survey (ENCA 1997-1998) ${ }^{15}$, a representative sample of the Canarian general population between 6- and 75-year-old was selected by a two-stage stratified sampling method. A total of 1747 individuals participated (67.2\% of the original sample). ENCA included two individual questionnaires about diet, lifestyle and health status. Anthropometric variables and blood pressure were also measured. Participants in these home surveys were solicited to have a blood extraction in order to determine biochemical parameters. Seven hundred and eighty-two subjects participated in the biochemical phase (44.8\% of the ENCA participants). The present study is based on a sub-sample of 578 adults $\geq 18$ years ( 249 men and 329 women).

The study was approved by the Institutional Committee of Ethics of the Canarian Health Service, and all the study patients gave written informed consent. Details on the methodology have been published elsewhere ${ }^{16}$.

\section{Nutritional assessment}

The usual food intake in the past 12 months was registered by a semiquantitative Food Frequency Questionnaire (FFQ), including 81 food items. Participants were asked to report how many times and how frequently they consumed these items, selecting one out of five frequency categories (ranging from 'never' to 'daily'). Referred intakes were transformed into grams per day. The FFQ is available online ${ }^{15}$. Total energy intake and macronutrient intakes were calculated from the FFQ using the Spanish food composition database developed by Mataix et al. ${ }^{17}$, complemented with French tables ${ }^{18}$. The specific methodology has been published elsewhere ${ }^{19}$.

In order to assess the adherence to an MD pattern, a specific score was calculated, based on ten food items. The ten food items were considered as follows:

(1) Cereal: white bread, whole grain bread, pasta, rice, breakfast sweetened cereals, gofio (roasted wheat or corn flour) and cookies.

(2) Fruit: apples, avocadoes, oranges, bananas, papayas, natural fruit juice and jam.

(3) Vegetables: vegetable soup, lettuce, boiled vegetables, tomatoes, onions and other vegetables.

(4) Legumes.

(5) Fish: blue fish, white fish, seafood and octopus.

(6) Nuts.

(7) Alcohol from red wine (one glass equivalent to $100 \mathrm{ml}$ of ethanol at $12 \%)$.

(8) Monounsaturated to saturated fatty acids ratio (MUFA/SFA ratio).

(9) Whole-fat dairy products: whole-fat milk, caramel custard, yoghurt, cream, cheese, margarine and butter. 
(10) Red meat and derivatives: beef, pork, ham, sausages and similar food items, liver and tripe.

Daily intakes of these foods items (in $\mathrm{g} \mathrm{day}^{-1}$ ) were adjusted to $2500 \mathrm{kcal}$ in men and $2000 \mathrm{kcal}$ in women. Then, sex-specific tertiles of the intakes of these ten food items were calculated. Three points were given to the subjects in the third tertile of cereal, fruit, vegetables, fish, nuts and MUFA/SFA ratio; two points to the subjects in the second tertile and one point to the subjects in the first tertile. Whole-fat dairy products and red meat intake received an inverse marking system (three points to the first tertile and one point to the third one). With respect to the alcohol intake from red wine, three points were assigned to moderate consumers (0.1-19.9 and 0.139.9 day $^{-1}$ in women and men, respectively) and one point to non-consumers. There were no subjects consuming higher amounts of alcohol from red wine. Finally, the total sum of individual marks in every food item was calculated given the total Mediterranean score (ranging from 10 to 30).

\section{Metabolic Syndrome}

The definition of MS used in our work was the one established by the National Cholesterol Education Program's Adult Treatment Panel III (ATP III) ${ }^{2}$. A participant was considered to have MS if three or more of the following criteria were present:

1. Abdominal obesity, defined by waist circumference: Men $>102 \mathrm{~cm}$; Women $>88 \mathrm{~cm}$. Waist circumference was collected with the subject standing, taking as reference half of the distance between the iliac crest and the lowest rib margin. A non-stretch metric measure tape was utilised. There were $2.8 \%$ of missing data for this variable.

2. Triglycerides $\geq 150 \mathrm{mg} \mathrm{dl}^{-1}$ in serum (missing data $=1.2 \%)$.

3. HDL cholesterol $<40$ and $<50 \mathrm{mg} \mathrm{dl}^{-1}$ for men and women, respectively. All lipid variables were obtained by standardised chemical methods and spectrophotometry (missing data $=1.3 \%$ ).

4. Blood pressure $\geq 130 / 85 \mathrm{mmHg}$. Blood pressure determination was made in the dominant arm of a seated subject with an automatic tensiometer, separating the first and the second readings by $10 \mathrm{~min}$. The mean of both readings was determined. This criterion was also applied to subjects who were receiving medical treatment with antihypertensive medication ( missing data $=2.3 \%$ ).

5. Fasting glucose $\geq 110 \mathrm{mgdl}^{-1}$. Subjects had been fasting for $12 \mathrm{~h}$ and the glucose was also obtained by standardised chemical methods. This criterion was also applied to subjects who were receiving antidiabetic medication (insulin or oral agents) (missing data $=1.2 \%)$.

\section{Insulin resistance}

Insulin resistance was considered with two variables: high fasting insulinaemia or high HOMA index. The HOMA index was calculated with the formula = [(insulin $\times$ glycaemia)/405]. Using the methodology described by Ascaso et al. ${ }^{9}$, a control population without insulin resistance was used. The control population was selected from those ENCA subjects that fulfil the inclusion criteria (age 30-60 years; absence of family antecedents of diabetes, hypertension or cardiovascular events (acute myocardial infarction/ictus); absence of personal antecedents of diabetes or cardiovascular disease; fasting glycaemia levels $<110 \mathrm{mg} \mathrm{dl}^{-1}$; blood pressure $<140$ / $90 \mathrm{mmHg}$; absence of antihypertensive medication; triglycerides level $<150 \mathrm{mg} \mathrm{dl}^{-1}$; body mass index $<25 \mathrm{~kg} \mathrm{~m}^{-2}$; waist circumference $<102 \mathrm{~cm}$ (men) or $<88 \mathrm{~cm}$ (women)). Percentile 90 of fasting insulinaemia in that control population was $14.0195 \mu \mathrm{U} \mathrm{ml}^{-1}$, whereas percentile 90 of HOMA index was $2.8590 \mathrm{UI}$.

\section{Sociodemographic and lifestyle variables}

The variables assessed were: sex, age, educational level (less than elementary, elementary, high school and university), physical activity in free time (sedentary, light, moderate or vigorous), body mass index (BMI, weight in kilogram per height in square metre categorised in $<25$, $25-29.9$ and $\geq 30 \mathrm{~kg} \mathrm{~m}^{-2}$ ), tobacco consumption (smoking, no smoking and ex-smokers), having followed any kind of regimen diet in the past 12 months (yes or no) and total energy intake.

\section{Statistical analysis}

The categorical variables were expressed as percentages. Differences between MS and non-MS subjects were evaluated with $\chi^{2}$ analyses. Continuous variables were expressed as means and standard deviations (SDs) if they followed a normal distribution, or as medians (25th-75th percentiles) in the case of skewed distributions. Differences between MS and non-MS were evaluated with the Student's $t$-test or, if not normally distributed, with the Mann-Whitney $U$ test.

A multivariate logistic regression was used to calculate the odds ratios (ORs) for MS prevalence, and for the prevalence of every MS criterion. For these calculations, first tertile of adherence of MD and first tertile of intake of each ten items of the MD index were used as reference category. $P<0.05$ was considered to be significant. All the statistics were performed with the SPSS software (release 11.0; SPSS Inc., Chicago, IL, USA).

\section{Results}

From the total study population, 141 patients (24.4\%) met the ATP III definition of MS. The prevalence of every criterion is summarised in Table 1. The most frequent criteria were elevated blood pressure (50.2\%), followed by 
Table 1 Prevalence of metabolic syndrome, MS criteria and insulin resistance by sex. ENCA Study, $n=578$

\begin{tabular}{|c|c|c|c|c|c|c|c|}
\hline \multirow[b]{2}{*}{ Criteria } & \multicolumn{2}{|c|}{ Total } & \multicolumn{2}{|c|}{ Men } & \multicolumn{2}{|c|}{ Women } & \multirow[b]{2}{*}{$P$} \\
\hline & $n$ & $\%$ & $n$ & $\%$ & $n$ & $\%$ & \\
\hline MS & 141 & 24.4 & 61 & 24.5 & 80 & 24.3 & NS \\
\hline \multicolumn{8}{|l|}{ Blood pressure criteria } \\
\hline $\mathrm{SBP} \geq 130$ and/or $\mathrm{DBP} \geq 85$ & 284 & 49.1 & 157 & 63.1 & 127 & 38.6 & 0.001 \\
\hline Antihypertensive medication & 67 & 11.6 & 22 & 8.8 & 45 & 13.7 & 0.072 \\
\hline Any & 295 & 50.2 & 161 & 64.1 & 134 & 39.8 & 0.001 \\
\hline \multicolumn{8}{|l|}{ HDL Cholesterol criteria } \\
\hline $\mathrm{HDL}<40 \mathrm{mg} \mathrm{dl}^{-1}(\mathrm{M}),<50 \mathrm{mg} \mathrm{dl}^{-1}(\mathrm{~W})$ & 198 & 34.3 & 66 & 26.5 & 132 & 40.1 & 0.001 \\
\hline \multicolumn{8}{|l|}{ Triglyceridaemia criteria } \\
\hline Triglycerides $\geq 150 \mathrm{mg} \mathrm{dl}^{-1}$ & 149 & 25.8 & 79 & 31.7 & 70 & 21.3 & 0.004 \\
\hline \multicolumn{8}{|l|}{ Central obesity criteria } \\
\hline Waist circ. $>102 \mathrm{~cm}(\mathrm{M}),>88 \mathrm{~cm}(\mathrm{~W})$ & 201 & 34.8 & 76 & 30.5 & 125 & 38.0 & 0.062 \\
\hline \multicolumn{8}{|l|}{ Glycaemia criteria } \\
\hline Fasting glucose $\geq 10 \mathrm{mg} \mathrm{dl}^{-1}$ & 61 & 10.6 & 30 & 12.0 & 31 & 9.4 & NS \\
\hline Antidiabetic medication $^{1}$ & 24 & 4.2 & 12 & 4.8 & 12 & 3.6 & NS \\
\hline Any & 67 & 11.6 & 35 & 14.1 & 32 & 9.7 & NS \\
\hline \multicolumn{8}{|l|}{ Insulin resistance } \\
\hline Insulinaemia $>14.02 \mu \mathrm{U} \mathrm{ml}^{-1}$ & 183 & 32.3 & 85 & 35.1 & 98 & 30.2 & NS \\
\hline HOMA index $>2.86$ UI & 154 & 27.2 & 72 & 29.8 & 82 & 25.3 & NS \\
\hline
\end{tabular}

$n$, number of subjects; NS, non-significative; HDL, high-density lipoprotein cholesterol; M, men; W, women; SBP, systolic blood pressure; DBP, diastolic blood pressure.

${ }^{1}$ Antidiabetic medication, insulin or oral hypoglycemic agents.

central obesity and low HDL cholesterol. Men showed a higher prevalence of hypertriglyceridaemia and elevated blood pressure, while women showed higher prevalence of abdominal obesity and low HDL cholesterol (all differences $P<0.05$, except for central obesity, $P=0.06$ ).

The prevalence of every criterion by age group is shown in Fig. 1. In younger groups, the most prevalent criteria were low HDL cholesterol and hypertension. From 55 years on, more than $80 \%$ of the subjects fulfil the elevated blood pressure criterion, and more than 50\% fulfil the central obesity criterion.

The insulin-resistance prevalence was $32.3 \%$ when high insulinaemic level was used and 27.2\% when high HOMA index was used. No relevant differences by sex were detected. The prevalence of insulin resistance increases significantly with age.

In an MD score ranging from 10 to 30 points, the mean score of ENCA subjects was 19.7 points (SD 3.15). The score was higher in men and older subjects, as shown in Fig. 2.

The score was higher in MS subjects [mean score 20.2 (SD 3.2)] than in non-MS subjects [mean score 19.5 (SD 3.1)], $P<0.05$. In order to consider all the influential variables, a multivariable regression model was developed. Once adjusted, MD adherence was not related to MS prevalence, with an OR (95\% CI) of 1.39 (0.75-2.59) for subjects in the second tertile of adherence and an OR 1.37 (0.76-2.46) for subjects in the third tertile of adherence, with respect to the first tertile.

Individual criteria of MS were also considered. Crude analysis showed that the subjects who presented glycaemia criterion (high fasting glycaemia or antidiabetic treatment) showed a higher MD score [mean score 21.0
(SD 2.9)] than the subjects without this criterion [mean score 19.5 (SD 3.1)] $P<0.05$. Once adjusted (Table 2), the subjects in the third tertile of adherence to the MD pattern (score of adherence $\geq 21$ ) presented a $70 \%$ lower prevalence of the blood pressure criterion ( $P$ for tendency 0.051 ) but 2.5 times more prevalence of the glycaemia criterion with respect to the first tertile (score of adherence $\leq 18$ ). The rest of MS criteria and the insulin-resistance prevalence were not significantly associated with the MD score.

The association of the ten food items of the MD pattern with the five MS criteria and insulin-resistance prevalence were considered separately (Table 3).

Red meat intake was associated with a higher prevalence of the blood pressure criterion (elevated blood pressure or antihypertensive treatment), $P$ for tendency 0.028. Moderate alcohol intake from red wine was associated with a lower prevalence of this criterion in women.

With respect to the two dislipemic criteria (high triglyceridaemia and low HDL cholesterol), moderate alcohol intake was associated with a lower prevalence of both criteria, but it was significant only for HDL cholesterol in men. Fruit intake also showed a protective effect on both dislipemic criteria. On the contrary, vegetable intake was associated with a higher prevalence of dislipemia. In both cases, it was significant only in the case of triglyceride criterion.

With respect to the glycaemic homeostasis (glycaemia criterion and insulin-resistance prevalence), cereal intake showed a protective effect, significative in the case of insulin resistance measured by high insulinaemia levels ( $P$ for tendency 0.020). Fruit intake showed a relevant 


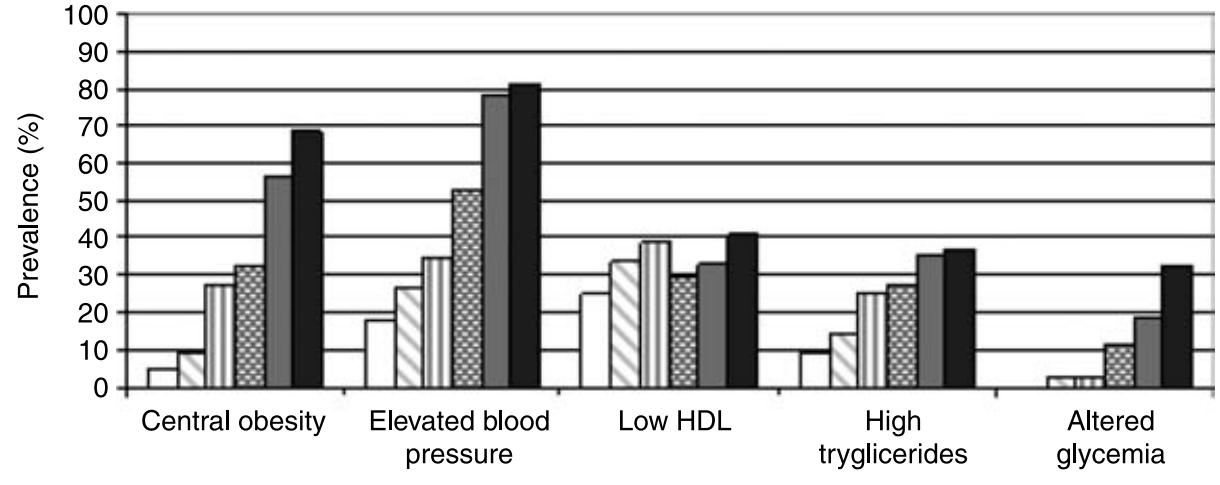

Metabolic syndrome criteria

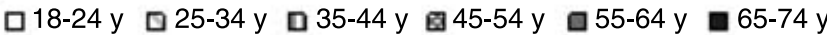

Fig. 1 Prevalence of metabolic syndrome criteria by age group. ENCA Study, $n=578$

protective effect over high HOMA index. Whole-fat dairy products showed a protective effect on the glycaemia criterion (high fasting glycaemia or antidiabetic treatment), but it showed the reverse effect on insulin resistance, although not significant in later. High monounsaturated fatty acid intake (with respect to saturated intake) showed a protective effect on the glycaemia criterion and insulin resistance when measured by the two variables (insulinaemia and HOMA index), $P$ for tendency $=0.06$ for both. Finally, moderate intake of alcohol from red wine showed a protective effect on the glycaemic homeostasis, especially in men (not significant).

No noticeable association was observed for the central obesity criterion.

\section{Discussion}

One in every four adults presented MS in this representative sample of Spanish population. This prevalence $^{6}$ is one of the highest in the European population-based studies and similar to prevalence described in the $\mathrm{USA}^{20}$. A higher adherence to the MD was related with a lower prevalence of the blood pressure criterion but a higher prevalence of the glycaemia one.

Subjects with high adherence to the MD index (third tertile, score $\geq 21$ ) showed $70 \%$ less prevalence of the blood pressure criterion (elevated blood pressure or antihypertensive treatment) than the subjects with low adherence (first tertile, score $\leq 18$ ), $P$ for tendency 0.051 . In the Greek-EPIC cohort $^{21}$, an inverse association between MD adherence and blood pressure has also been described.

The food items involved in the protective effect of the MD on the blood pressure criterion in the ENCA Study were lower red meat intake $\left(<40 \mathrm{~g} \mathrm{day}^{-1}\right)$ and moderate alcohol intake from red wine $\left(0.1-19.9 \mathrm{~g} \mathrm{day}^{-1}\right.$ in women). Their protective effects remained even when macro- and micronutrients intake (including proteins, saturated fatty acids, sodium, potassium and alcohol) were included in the model (data not shown).

Recently, a 7-year follow-up study of JapaneseBrazilians aged $40-79$ years ${ }^{22}$ showed that men with the highest tertile of red meat consumption presented a 4.7fold increase in the risk of developing MS. The red meat

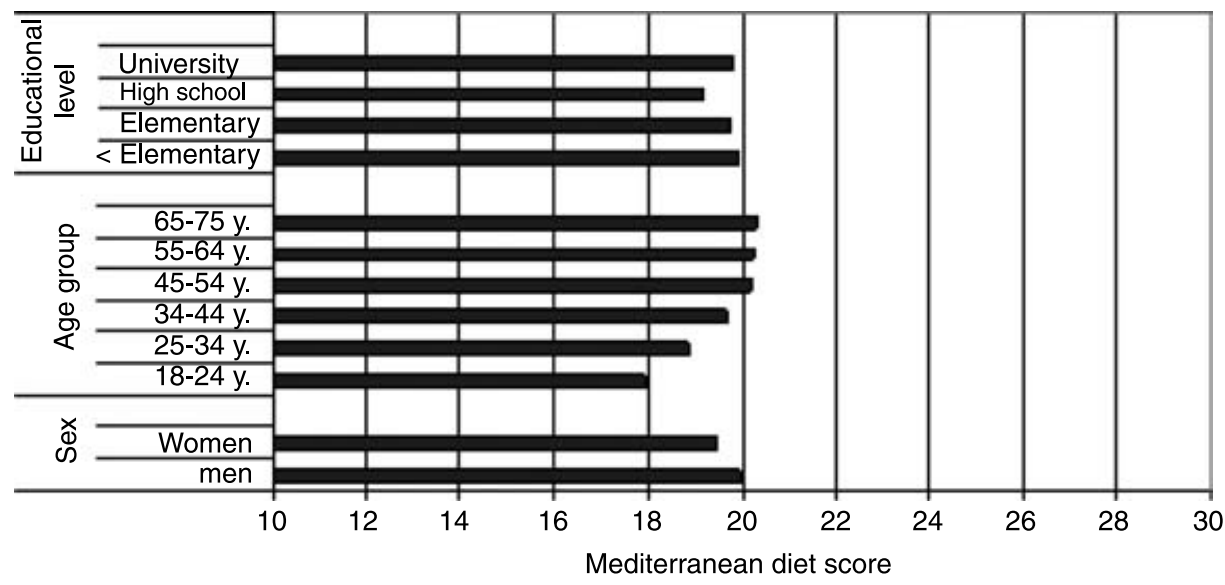

Fig. 2 Mediterranean diet (MD) score, by sex, age group and educational level. ENCA Study, $n=578$ 
Table 2 Odds ratio of presence of metabolic syndrome (MS) criteria and insulin resistance, by tertile of adherence to Mediterranean diet (MD). ENCA Study, $n=532$

\begin{tabular}{|c|c|c|c|c|c|c|}
\hline \multirow[b]{2}{*}{ Criteria } & \multirow[b]{2}{*}{ MD Score } & \multirow{2}{*}{$\begin{array}{l}\mathrm{OR}^{1} \text { of } \\
\text { Criteria }\end{array}$} & \multicolumn{2}{|c|}{$95 \% \mathrm{Cl}$} & \multirow[b]{2}{*}{$P$} & \multirow[b]{2}{*}{$P$ tend } \\
\hline & & & Inf & Sup & & \\
\hline \multirow[t]{3}{*}{ Blood pressure criteria } & Tertile 1 & 1.00 & & & & \\
\hline & Tertile 2 & 0.88 & 0.52 & 1.52 & & \\
\hline & Tertile 3 & 0.58 & 0.34 & 0.99 & 0.045 & 0.051 \\
\hline \multirow[t]{3}{*}{ HDL Cholesterol criteria } & Tertile 1 & 1.00 & & & & \\
\hline & Tertile 2 & 0.88 & 0.55 & 1.42 & & \\
\hline & Tertile 3 & 0.90 & 0.56 & 1.42 & NS & NS \\
\hline \multirow{3}{*}{ Triglyceridaemia criteria } & Tertile 1 & 1.00 & & & & \\
\hline & Tertile 2 & 1.22 & 0.72 & 2.06 & & \\
\hline & Tertile 3 & 1.05 & 0.63 & 1.75 & NS & NS \\
\hline \multirow[t]{3}{*}{ Central obesity criteria } & Tertile 1 & 1.00 & & & & \\
\hline & Tertile 2 & 0.98 & 0.48 & 2.02 & & \\
\hline & Tertile 3 & 0.77 & 0.38 & 1.56 & NS & NS \\
\hline \multirow[t]{3}{*}{ Glycaemia criteria } & Tertile 1 & 1.00 & & & & \\
\hline & Tertile 2 & 2.17 & 0.94 & 4.99 & & \\
\hline & Tertile 3 & 2.46 & 1.13 & 5.37 & 0.024 & 0.083 \\
\hline \multirow[t]{3}{*}{ Insulin $>14.02$} & Tertile 1 & 1.00 & & & & \\
\hline & Tertile 2 & 0.76 & 0.43 & 1.34 & & \\
\hline & Tertile 3 & 0.67 & 0.39 & 1.17 & NS & NS \\
\hline \multirow[t]{3}{*}{ HOMA > 2.86} & Tertile 1 & 1.00 & & & & \\
\hline & Tertile 2 & 0.89 & 0.52 & 1.51 & & \\
\hline & Tertile 3 & 0.94 & 0.56 & 1.58 & NS & NS \\
\hline
\end{tabular}

effect on blood pressure has extensively been described. In a 7-year follow-up study carried out in 1700 US men, it was observed that those men eating $>80 \mathrm{~g} \mathrm{day}^{-1}$ of meat showed higher blood pressure levels than men eating $<80$ g per day ${ }^{23}$. In the Oxford-EPIC cohort ${ }^{24}$ more than 11000 subjects, aged 20-79 years, were studied, and those who did not refer meat, fish, eggs or dairy products consumption showed $2-4 \mathrm{mmHg}$ less in their mean blood pressure levels than regular meat consumers. In the Nurses's Health Study ${ }^{25}, 0.11 \mathrm{mmHg}$ increased in systolic blood pressure was observed for every quintile of increase in meat intake. Similar results were described in the Coronary Artery Risk Development in Young Adults (CARDIA) Study ${ }^{26}$, while plant food intake (grains, fruit, vegetables, nuts and legumes) was inversely related to elevated blood pressure. In the ENCA Study, vegetables, nuts and legumes intakes were also related with lower prevalence of the blood pressure criterion (no significant).

With respect to the protective effect showed by red wine, the ENCA Study showed that the women who refer moderate alcohol intake $\left(0.1-19.9 \mathrm{~g} \mathrm{day}^{-1}\right.$ of alcohol from red wine) presented a two-fold decrease prevalence of the blood pressure criterion with respect to non-consumers. A protective effect of moderate alcohol intake on cardiovascular profile in women has also been described in another Spanish population-based study ${ }^{27}$.

Nevertheless, it must be highlighted that a deleterious effect of excessive alcohol intake on blood pressure has also been extensively described. Thus, in the National Heart, Lung and Blood Institute Family Heart Study carried out with a USA adult population group ${ }^{28}$, a protective effect of $0.1-12 \mathrm{~g} \mathrm{day}^{-1}$ of alcohol intake on the blood pressure criterion was described, especially for women. However, when the alcohol intake was $>24 \mathrm{~g} \mathrm{day}^{-1}$, an incremental risk was described, especially in men.

The food items included in the MD score showed relevant associations with the two dislipemic criteria included in the MS definition (high triglyceridaemia and low HDL cholesterol). Moderate alcohol intake was related to a lower prevalence of low HDL cholesterol, of significance only for men. This effect was maintained when macro- and micronutrients were included in the model, even when total alcohol intake was included [OR 0.56 (95\% CI $0.37-0.85)]$.

The protective effect of alcohol intake on HDL cholesterol has been described in other studies. In the National Heart Study, previously mentioned ${ }^{28}$ subjects with high alcohol intakes presented a lower prevalence of the HDL criterion than non-alcohol consumers. In the DESIR French study ${ }^{29}$, alcohol consumption was also associated with higher HDL cholesterol serum levels in both sexes. Similar results were mentioned in a study ${ }^{30}$ carried out in Brazil. Finally, in the other article of the Spanish population-based study previously mentioned ${ }^{31}$, alcohol consumption showed a positive effect over HDL cholesterol serum levels in men. This protective effect could be partially explained by a direct effect of alcohol on HDL cholesterol synthesis, and by a modification of the activity of the lipoprotein lipase, hepatic lipase and cholesterol-ester transfer protein ${ }^{31}$. 


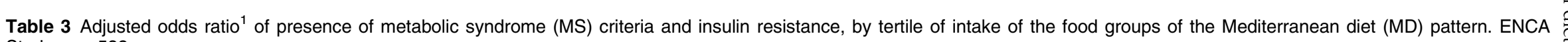
Study, $n=532$

\begin{tabular}{|c|c|c|c|c|c|c|c|}
\hline & $\begin{array}{l}\text { Blood pressure } \\
\text { criteria }\end{array}$ & $\begin{array}{l}\text { HDL cholesterol } \\
\text { criteria }\end{array}$ & $\begin{array}{l}\text { Triglyceride } \\
\text { criteria }\end{array}$ & Central obesity criteria & $\begin{array}{l}\text { Glycaemia } \\
\text { criteria }\end{array}$ & Insulin $>14$ & HOMA $>3$ \\
\hline Cereals T1 (ref) & 1.00 & 1.00 & 1.00 & 1.00 & 1.00 & 1.00 & 1.00 \\
\hline T2 & $1.40(0.80-2.46)$ & $0.79(0.50-1.26)$ & $1.37(0.79-2.37)$ & $0.92(0.43-1.57)$ & $0.81(0.36-1.80)$ & $0.53(0.30-0.96)^{\star}$ & $0.66(0.38-1.13)$ \\
\hline T3 & $1.63(0.92-2.46)$ & $0.85(0.54-1.35)$ & $0.89(0.51-1.57)$ & $1.16(0.56-2.42)$ & $0.86(0.39-1.89)$ & $0.52(0.29-0.94)^{\star}$ & $0.70(0.41-1.21)$ \\
\hline Fruit T1 (ref) & 1.00 & 1.00 & 1.00 & 1.00 & 1.00 & 1.00 & 1.00 \\
\hline T2 & $0.85(0.48-1.50)$ & $0.69(0.42-1.13)$ & $0.49(0.28-0.88)^{\star}$ & $0.68(0.33-1.39)$ & $1.19(0.50-2.85)$ & $0.63(0.34-1.18)$ & $0.49(0.28-0.88)^{\star}$ \\
\hline T3 & $1.15(0.65-2.02)$ & $0.77(0.47-1.25)$ & $0.69(0.40-1.18)$ & $0.86(0.44-1.70)$ & $1.85(0.82-4.19)$ & $1.30(0.73-2.32)$ & $0.91(0.53-1.57)$ \\
\hline Vegetables T1 (ref) & 1.00 & 1.00 & 1.00 & 1.00 & 1.00 & 1.00 & 1.00 \\
\hline T2 & $0.97(0.55-1.72)$ & $1.31(0.82-2.08)$ & $1.76(1.02-3.05)^{\star}$ & $1.32(0.62-2.28)$ & $1.61(0.66-3.90)$ & $1.36(0.75-2.46)$ & $1.36(0.78-2.37)$ \\
\hline T3 & $0.79(0.42-1.48)$ & $1.17(0.71-1.92)$ & $1.29(0.70-2.38)$ & $0.94(0.46-1.03)$ & $1.60(0.63-4.06)$ & $0.90(0.47-1.73)$ & $1.25(0.68-2.31)$ \\
\hline Legumes T1 (ref) & 1.00 & 1.00 & 1.00 & 1.00 & 1.00 & 1.00 & 1.00 \\
\hline T2 & $0.92(0.53-1.60)$ & $1.05(0.66-1.68)$ & $1.30(0.75-2.25)$ & $0.67(0.34-1.32)$ & $2.16(0.92-5.04)$ & $0.66(0.36-1.19)$ & $0.67(0.34-1.32)$ \\
\hline T3 & $0.92(0.53-1.62)$ & $1.36(0.84-2.19)$ & $1.29(0.72-2.32)$ & $0.94(0.46-1.93)$ & $1.82(0.71-4.68)$ & $1.41(0.76-2.59)$ & $0.94(0.46-1.93)$ \\
\hline Fish T1 (ref) & 1.00 & 1.00 & 1.00 & 1.00 & 1.00 & 1.00 & 1.00 \\
\hline T2 & $0.97(0.56-1.71)$ & $0.79(0.50-1.26)$ & $0.61(0.35-1.06)$ & $0.61(0.29-1.33)$ & $0.57(0.24-1.36)$ & $1.24(0.67-2.27)$ & $0.61(0.29-1.33)$ \\
\hline T3 & $1.13(0.63-2.03)$ & $0.97(0.61-1.56)$ & $0.83(0.47-1.45)$ & $0.50(0.23-1.10)$ & $1.13(0.49-2.62)$ & $1.31(0.71-2.43)$ & $0.50(0.23-1.10)$ \\
\hline Nuts T1 (ref) & 1.00 & 1.00 & 1.00 & 1.00 & 1.00 & 1.00 & 1.00 \\
\hline T2 & $0.73(0.41-1.28)$ & $0.77(0.48-1.23)$ & $1.34(0.81-2.22)$ & $1.31(0.62-2.80)$ & $0.70(0.30-1.65)$ & $0.92(0.51-1.65)$ & $0.84(0.48-1.45)$ \\
\hline T3 & $0.83(0.47-1.46)$ & $0.89(0.56-1.41)$ & $0.91(0.53-1.55)$ & $0.88(0.41-1.90)$ & $1.86(0.84-4.12)$ & $0.93(0.51-1.71)$ & $1.23(0.70-2.14)$ \\
\hline Whole-fat dairy $\mathrm{T} 1$ (ref) & 1.00 & 1.00 & 1.00 & 1.00 & 1.00 & 1.00 & 1.00 \\
\hline T2 & $1.68(0.96-2.97)$ & $1.26(0.80-1.99)$ & $0.62(0.35-1.09)$ & $1.70(0.78-3.73)$ & $0.68(0.31-1.49)$ & $1.48(0.81-2.69)$ & $1.70(0.78-3.73)$ \\
\hline T3 & $1.71(0.94-3.11)$ & $0.90(0.56-1.44)$ & $0.71(0.39-1.31)$ & $2.03(0.89-4.64)$ & $0.27(0.10-0.75)^{\star}$ & $0.98(0.51-1.89)$ & $2.03(0.89-4.64)$ \\
\hline Red meat T1 (ref) & 1.00 & 1.00 & 1.00 & 1.00 & 1.00 & 1.00 & 1.00 \\
\hline T2 & $1.95(1.10-3.45)^{\star}$ & $0.94(0.59-1.50)$ & $1.34(0.81-2.22)$ & $0.69(0.35-1.40)$ & $0.89(0.43-1.86)$ & $0.85(0.48-1.52)$ & $0.69(0.35-1.40)$ \\
\hline T3 & $2.10(1.16-3.79)^{\star}$ & $1.00(0.62-1.61)$ & $0.87(0.51-1.49)$ & $1.01(0.50-2.07)$ & $0.54(0.23-1.26)$ & $1.07(0.59-1.95)$ & $1.01(0.50-2.07)$ \\
\hline Mufa/sfa ratio $\mathrm{T} 1$ (ref) & 1.00 & 1.00 & 1.00 & 1.00 & 1.00 & 1.00 & 1.00 \\
\hline T2 & $0.77(0.44-1.35)$ & $0.81(0.52-1.31)$ & $0.85(0.50-1.43)$ & $1.14(0.53-2.49)$ & $0.52(0.23-1.19)$ & $0.55(0.30-0.99)^{*}$ & $0.63(0.36-1.09)$ \\
\hline T3 & $0.79(0.43-1.46)$ & $0.93(0.59-1.48)$ & $1.28(0.77-2.11)$ & $1.09(0.48-2.52)$ & $0.44(0.19-1.02)$ & $0.53(0.28-1.01)$ & $0.49(0.27-0.89)^{*}$ \\
\hline Red wine alcohol T1 (ref) & 1.00 & 1.00 & 1.00 & 1.00 & 1.00 & 1.00 & 1.00 \\
\hline T2 (men) & $1.13(0.77-1.69)$ & $0.49(0.33-0.73)^{\star *}$ & $0.83(0.45-1.55)$ & $1.06(0.43-2.65)$ & $0.58(0.33-1.01)$ & $0.81(0.56-1.18)$ & $0.90(0.63-1.29)$ \\
\hline T2 (women) & $0.46(0.29-0.74)^{\star *}$ & $0.85(0.46-1.56)$ & $0.96(0.62-1.49)$ & $0.84(0.47-1.51)$ & $1.56(0.82-2.98)$ & $0.85(0.53-1.36)$ & $0.82(0.54-1.26)$ \\
\hline
\end{tabular}

T1, first tertile; T2, second tertile; T3, third tertile; NA, not applicable (only two groups); MUFA/SFA, monounsaturated to saturated fatty acids ratio.

${ }^{1}$ Adjusted by sex (except red wine alcohol intake), age, educational level, physical activity level, BMI, tobacco consumption, diet in the past 12 months, energy intake and intake of rest of food groups included in the MD score. ${ }^{\star} P<0.05 ;{ }^{* \star} P<0.01$ 
Fruit intake also showed a protective effect on both dislipemic criteria. Moderate fruit intake (mean intake $375 \mathrm{~g} \mathrm{day}^{-1}$ ) was associated with a twofold decrease in triglyceride criterion prevalence with respect to low fruit intake $\left(<250 \mathrm{~g} \mathrm{day}^{-1}\right)$, whereas high fruit intake $\left(>450 \mathrm{~g} \mathrm{day}^{-1}\right)$ showed no significant association. The protective effect of moderate fruit intake remained even when macro- and micronutrients were included in the model (1.85-fold decrease for the second tertile of fruit intake). In the Baltimore Longitudinal Study of Ageing ${ }^{32}$, subjects with a 'healthier' food pattern, where $10 \%$ of their energy was provided by fruit, presented 16\% lower triglyceride serum levels than subjects whose fruit-energy intake was $<5 \%$. Some randomised controlled studies ${ }^{33}$ have shown that fruit supplementation for one month decreases triglycerides levels by $12 \%$ in a high risk population (hypercholesterolaemic patients after coronary bypass surgery), and lower levels of total cholesterol and LDL cholesterol were also observed. In the ENCA Study, fruit intake showed a protective effect on low HDL cholesterol levels (Table 3), and also on high LDL cholesterol level (LDL $\geq 130 \mathrm{mg} \mathrm{dl}^{-1}$ ), with and OR 0.59 (95\% CI 0.35-0.98) for the second tertile and 0.53 (95\% CI $0.32-0.90$ ) for the third tertile, with respect to the first fruit intake tertile (all $P<0.05$ ).

With respect to the vegetable intake, an unexpected higher prevalence of the triglyceridaemia criterion was observed in subjects referring medium intakes of vegetables (mean vegetable intake $400 \mathrm{~g} \mathrm{day}^{-1}$ ) with respect to the lowest intake $\left(<200 \mathrm{~g} \mathrm{day}^{-1}\right)$, even when macro- and micronutrients intake were considered. Once again, the highest tertile showed no relevant association. In the Framingham Offspring Cohort Study ${ }^{34}$, fibre intake from vegetables was associated with higher (although non-significant) risks of developing MS (OR 1.15). The association observed in the ENCA Study could be due to the cross-sectional design of the study, and subjects with diagnosed hypertriglyceridaemia could be following a healthier diet with increased intakes of vegetables. Nevertheless, the exclusion of subjects that refer being on a diet in the past 12 months did not materially change the results, with an OR of present triglyceridaemia criterion of 1.84 (95\% CI 0.99-3.41) for the second tertile and 1.42 (95\% CI $0.70-2.87)$ for the third tertile, with respect to the first tertile. Those results should be assessed in larger prospective studies.

Finally, the MD influence on glucose homeostasis was assessed. As Table 2 shows, the subjects in the highest tertile of MS adherence presented a 2.5-fold increase in glycaemic criteria (high fasting glycaemia or antidiabetic treatment), although no worth-mentioning effect was seen on the insulin-resistance criterion. Subjects with higher intakes of whole-fat dairy products (third tertile, mean intake $600 \mathrm{~g} \mathrm{day}^{-1}$ ) showed a 3.7-fold decreased prevalence of the glycaemic criterion with respect to subjects with lower intakes (first tertile, intakes $<140 \mathrm{~g} \mathrm{day}^{-1}$ ). The results remained even when macro- and micronutrients intakes were considered. An opposite effect was seen on the insulin-resistance criterion (not relevant).

With respect to the glycaemia criterion, these results must be taken with caution, because the protective effect of whole-fat dairy products could also be due to the crosssectional design of the study. Most subjects that fulfil glycaemic criteria were previously known to be diabetic patients. Most of them were following a diet, and they have probably received nutritional counselling regarding a healthier diet (including low whole-fat dairy products intake). Nevertheless, high intake of whole-fat dairy products has been associated with lower weight gain ${ }^{35}$, and this factor would decrease the risk of developing diabetes. In the Women's Health Study carried out in the $\mathrm{USA}^{36}$, dairy products intake was associated with lower prevalence of MS, and the protective effect was stronger for whole-fat dairy products ( $P$ for tendency 0.002$)$ than for low-fat dairy products ( $P$ for tendency 0.07 ). Those results should be assessed in larger prospective studies.

Higher cereal intake was related with a lower prevalence of the glycaemic criterion and the insulinresistance criterion. The subjects referring cereal intake $>150 \mathrm{~g} \mathrm{day}^{-1}$ presented half the risk of hyperinsulinaemia than subjects with lower intakes. Moderate fruit intake (mean intake $375 \mathrm{~g} \mathrm{day}^{-1}$ ) was associated with a twofold decrease in high HOMA index prevalence. It was also associated with lower hyperinsulinaemia prevalence, although not significantly. The results remained even when macro- and micronutrients intakes were considered (OR 0.53 for the second tertile and 0.56 for the third tertile).

There are numerous studies analysing the relationship between carbohydrate intake and glucose homeostasis. With a similar methodology as the one used for the ENCA (cross-sectional population-based study), the Framingham Offspring Cohort Study ${ }^{34}$ showed that whole-grain cereals' and fibre intakes (especially, fibre from cereal and fibre from fruit) were associated with a lower mean HOMA index. In the Insulin Resistance Atherosclerosis Study (IRAS) $^{37}$, whole-grain intake was associated with higher insulin sensitivity and lower insulin levels. In the Inter99 Study $^{38}$, every $100 \mathrm{~g} \mathrm{day}^{-1}$ of increase in fruit and vegetable intake was related with a 0.99 UI decrease in HOMA index, the same decrease that was described for every $1 \%$ of energy provided by fructose (fruit sugar with low glycaemic index).

One possible pathophysiology explanation could be that whole-grain cereals' intake and low glycaemic index foods result in a significant decrease in the after-meal insulin response. This effect could be partially explained by the nutrient composition of those foods (fibre content), which results in a lower rate of gastric emptying and an increase satiation ${ }^{39}$.

Other components of cereals and fruit (like magnesium and vitamin E) have also been involved ${ }^{37}$. The IRAS 
authors mentioned that the inclusion of fibre and magnesium in their model attenuated the relationship between cereal intake and insulin sensitivity. Nevertheless, in the ENCA Study, the inclusion of these nutrients did not materially affect the described association.

The other food item that was related with glucose homeostasis was the monounsaturated to saturated fatty acids ratio. The subjects that refer intakes of MUFA higher than SFA (MUFA/SFA ratio > 1) showed a lower prevalence of elevated HOMA index, and a lower prevalence of hyperinsulinaemia. This protective role persists even when macro- and micronutrients were considered (OR for the second and the third tertiles 0.57 and 0.36 for HOMA and 0.49 and 0.41 for hyperinsulinaemia, respectively, compared with the first tertile). In an interesting review on carbohydrates and fats' effects on insulin resistance ${ }^{40}$, it was remarked that the substitution of a high SFA diet (MUFA/ SFA ratio 0.74) for a high MUFA diet (MUFA/SFA ratio 2.21) was related with a 10\% increase in insulin sensitivity. Olive oil is one of the main MUFA sources in the ENCA subjects, being consumed by $80 \%$ of the population ${ }^{41}$.

In a Spanish study, the prevalence of insulin resistance was 50\% lower in subjects that cooked with olive oil, compared with those that used other vegetable oils (sunflower seed or mixed) ${ }^{42}$. It has been mentioned that SFA worsens insulin resistance, whereas MUFA and PUFA improve it, due to a modification in the lipid composition of cell membranes in liver and muscle tissues, where the oleic acid concentration is high ${ }^{43}$. Other possible effects could be the regulation of gene expression related to insulin sensitivity ${ }^{43}$.

In conclusion, following a diet approaching the MD model, especially with low intake of red meat, moderate alcohol consumption and high intakes of fruit, cereals and monounsaturated fatty acids, has been related with a lower prevalence of MS criteria and insulin resistance in the general population.

\section{Acknowledgements}

This work was supported by the Canarian Health Service through a research agreement with the University of Las Palmas de Gran Canaria, and by the financial support of the INNOVA University Patronage Program 2004, from the Fundación Universitaria de Las Palmas-Clínica San Roque.

Authors acknowledge Dr. Iasías Naranjo who checked the English version.

\section{References}

1 World Health Organization. The World Health Report 2004. Statistical Annex. Annex Table 2: Deaths By Cause, Sex and Mortality Stratum in WHO Regions, Estimates For 2002. Available at: http://www.who.int/whr/2004/annex/topic/ en/annex_2_en.pdf (Accessed 14/09/2006).

2 National Institute of Health. Third Report of the National Cholesterol Education Program Expert Panel on Detection,
Evaluation, and Treatment of High Blood Cholesterol in Adults (Adult Treatment Panel III). National Institute of Health, 2002 NIH publication No. 02-5215. September 2002. Available at: http://www.nhlbi.nih.gov/guidelines/cholesterol/atp3full.pdf (Accessed 14/09/2006).

3 Serra-Majem L, Ribas L, Tresserras R, Ngo J, Salleras L. How could changes in diet explain changes in coronary heart disease mortality in Spain? The Spanish paradox. American Journal of Clinical Nutrition 1995; 61(Suppl 6): 1351S-9S.

4 Medrano MJ, Cerrato E, Boix R, Delgado-Rodríguez M. Factores de riesgo cardiovascular en la población española: meta-análisis de estudios transversales. Medicina Clinica 2005; 124(16): 606-12.

5 Serra-Majem L, Navarro MC, Laínez P, Ribas L, on behalf of the ENCA research team. Encuesta Nutricional de Canarias. Vol 2. Factores de riesgo cardiovascular. Santa Cruz de Tenerife: Servicio Canario de Salud, 1999. Available at: http://www.gobiernodecanarias.org/sanidad/scs/1/ plansalud/enca/ppal_enca.htm (Accessed 14/09/2006).

6 Álvarez León EE, Ribas Barba L, Serra-Majem L. Prevalencia del Síndrome Metabólico en la población de las Islas Canarias, España. Medicina Clinica 2003; 120(5): 172-4.

7 Ceriello A, Motz E. Is oxidative stress the pathogenic mechanism underlying insulin resistance, diabetes, and cardiovascular disease? The common soil hypothesis revisited. Arteriosclerosis, Thrombosis and Vascular Biology 2004; 24(5): 816-23.

8 Matthews DR, Hosker JP, Rudenski AS, Naylor BA, Treacher DF, Turner RC. Homeostasis model assessment: insulin resistance and beta-cell function from fasting plasma glucose and insulin concentrations in man. Diabetologia 1985; 28(7): 412-9.

9 Ascaso JF, Romero P, Real JT, Priego A, Valdecabres C, Carmena R. Cuantificación de insulinorresistencia con los valores de insulina basal e índice HOMA en una población no diabética. Medicina Clinica 2001; 117: 530-3.

10 Esposito K, Marfella R, Ciotola M, Di Palo C, Giugliano F, Giugliano G, D'Armiento M, D'Andrea F, Giugliano D. Effect of a Mediterranean-style diet on endothelial dysfunction and markers of vascular inflammation in the metabolic syndrome. A randomized trial. JAMA 2004; 292(12): 1440-6.

11 Michalsen A, Lehmann N, Pithan C, Knoblauch NT, Moebus S, Kannenberg F, Binder L, Budde T, Dobos GJ. Mediterranean diet has no effect on markers of inflammation and metabolic risk factors in patients with coronary artery disease. European Journal of Clinical Nutrition 2006; 60(4): 478-85.

12 Bach A, Serra-Majem L, Carrasco JL, Roman B, Ngo J, Bertomeu I, Obrador B. The use of indexes evaluating the adherence to the Mediterranean diet in epidemiological studies: a review. Public Health Nutrition 2006; 9(1A): $132-46$.

13 Serra-Majem Ll, Ngo J, Ribas L, Tur JA. Olive oil and the Mediterranean diet: beyond the rethoric. European Journal of Clinical Nutrition 2003; 57(S1): 2S-7S.

14 Trichopoulou A, Orfanos P, Norat T, Bueno-de-Mesquita B, Ocke MC, Peeters PH, et al. Modified Mediterranean diet and survival: EPIC-elderly prospective cohort study. BMJ 2005; 330: $991-7$.

15 Serra-Majem L, Armas A, Ribas L, on behalf of the ENCA research team. Encuesta Nutricional de Canarias Vol 1. Hábitos alimentarios y consumo de alimentos. Santa Cruz de Tenerife: Servicio Canario de Salud, 1999. Available at: http://www.gobiernodecanarias.org/sanidad/scs/1/plansalud/enca/ppal_enca.htm (Accessed 14/09/2006).

16 Serra-Majem L, Navarro MC, Ribas L, Laínez P. Epidemiology of cardiovascular risk factors in the Canary Islands (1997-98): a crossroads between the Mediterranean 
and Latin American models. CDV Prevention 2000; 3 $64-70$.

17 Mataix J, Mañas M, Martínez de Vitoria E. Tabla de composición de alimentos españoles, 3rd ed. Granada: Universidad de Granada, 1998.

18 Favier JC, Ireland-Ripert J, Toque C, Feinberg M. Répertoire Général des Aliments. Table de composition, 2nd ed. Versailles: Institut National de la Recherche Agronomique, 1995.

19 Henríquez P, Doreste J, Díaz-Cremades J, López-Blanco F, Álvarez-León E, Serra-Majem L. Folate status of adults living in the Canary Islands (Spain). International Journal for Vitamin and Nutrition Research 2004; 74(3): 187-92.

20 Ford ES, Giles WH, Dietz WH. Prevalence of the metabolic syndrome among US adults: findings from the third National Health and Nutrition Examination Survey. JAMA 2002; 287: 356-9.

21 Psaltopoulou T, Naska A, Orfanos P, Trichopoulos D, Mountokalakis T, Trichopoulou A. Olive oil, the Mediterranean diet, and arterial blood pressure: the Greek European Prospective Investigation into Cancer and Nutrition (EPIC) study. American Journal of Clinical Nutrition 2004; 80: 1012-8.

22 Damiao R, Castro TG, Cardoso MA, Gimeno SG, Ferreira SR, for the Japanese-Brazilian DS. Dietary intakes associated with metabolic syndrome in a cohort of Japanese ancestry. The British Journal of Nutrition 2006; 96(3): 532-8.

23 Miura K, Greenland P, Stamler J, Liu K, Daviglus ML, Nakagawa H. Relation of vegetable, fruit, and meat intake to 7-year blood pressure changes in middle-aged men: the Chicago Western Electric Study. American Journal of Epidemiology 2004; 159(6): 572-80.

24 Appleby P, Davey G, Key T. Hypertension and blood pressure among meat eaters, fish eaters, vegetarians and vegans in EPIC-Oxford. Public Health Nutrition 2002; 5(5): 645-54.

25 Ascherio A, Hennekens C, Willett WC, Sacks F, Rosner B, Manson J, Witteman J, Stampfer MJ. Prospective study of nutritional factors, blood pressure, and hypertension among US women. Hypertension 1996; 27(5): 1065-72.

26 Steffen LM, Kroenke CH, Yu X, Pereira MA, Slattery ML, Van Horn L, Gross MD, Jacobs DR Jr. Associations of plant food, dairy product, and meat intakes with 15 -y incidence of elevated blood pressure in young black and white adults: the Coronary Artery Risk Development in Young Adults (CARDIA) Study. American Journal of Clinical Nutrition 2005; 82(6): 1169-77.

27 Schroder H, Ferrández O, Jiménez Conde J, Sánchez-Font A, Marrugat J. Cardiovascular risk profile and type of alcohol beverage consumption: a population-based study. Annals of Nutrition \& Metabolism 2005; 49(2): 100-6.

28 Djousse L, Arnett DK, Eckfeldt JH, Province MA, Singer MR, Ellison RC. Alcohol consumption and metabolic syndrome: does the type of beverage matter? Obesity Research 2004; 12(9): $1375-85$.

29 Vernay M, Balkau B, Moreau JG, Sigalas J, Chesnier MC, Ducimetiere P. Desir study group. Alcohol consumption and insulin resistance syndrome parameters: associations and evolutions in a longitudinal analysis of the French DESIR cohort. Annals of Epidemiology 2004; 14(3): 209-14.
30 Schmid N, Salas Martins I, Hernán M, Velásquez-Meléndez G, Ascherio A. Food frequency consumption and lipoproteins serum levels in the population of an urban area, Brazil. Revista De Saúde Pública 2000; 34(4): 380-7.

31 Sentí M, Masiá R, Pena A, Elosua R, Aubó C, Bosch M, Sala J, Marrugat J. Determinantes antropométricos y dietéticos de la concentración sérica del colesterol de las lipoproteínas de alta densidad en un estudio de base poblacional. El estudio REGICOR. Revista Española de Cardiología 1998; 51: 979-87.

32 Newby PK, Muller D, Tucker KL. Associations of empirically derived eating patterns with plasma lipid biomarkers: a comparison of factor and cluster analysis methods. American Journal of Clinical Nutrition 2004; 80(3): 759-67.

33 Gorinstein S, Caspi A, Libman I, Katrich E, Lerner HT, Trakhtenberg S. Preventive effects of diets supplemented with sweetie fruits in hypercholesterolemic patients suffering from coronary artery disease. Preventive Medicine 2004; 38(6): $841-7$.

34 McKeown NM, Meigs JB, Saltzman E, Wilson PWF, Jacques $\mathrm{PF}$. Carbohydrate nutrition, insulin resistance, and the prevalence of the metabolic syndrome in the Framingham Offspring Cohort. Diabetes Care 2004; 27: 538-46.

35 Sánchez-Villegas A, Bes-Rastrollo M, Martínez-González MA, Serra-Majem Ll. Adherence to a Mediterranean dietary pattern and weight gain in a follow-up study: the SUN cohort. International Journal of Obesity (London) 2006; 30(2): 350-8.

36 Liu S, Song Y, Ford ES, Manson JE, Buring JE, Ridker PM. Dietary calcium vitamin D, and the prevalence of metabolic syndrome in middle-aged and older US women. Diabetes Care 2005; 28(12): 2926-32.

37 Liese AD, Roach AK, Sparks KC, et al. Whole-grain intake and insulin sensitivity: the Insulin Resistance Atherosclerosis Study. American Journal of Clinical Nutrition 2003; 78(5): 965-71.

38 Lau C, Færch K, Glümer C, Tetens I, Pedersen O, Carstensen $\mathrm{B}$, Jørgensen T, Borch-Johnsen K. Dietary glycemic index, glycemic fiber, simple sugars, and resistance: the Inter99 study. Diabetes Care 2005; 28: 1397-403.

39 Delzenne NM, Cani PD. A place for dietary fibre in the management of the metabolic syndrome. Current Opinion in Clinical Nutrition Metabolic Care 2005; 8(6): 636-40.

40 Hung T, Sievenpiper JL, Marchie A, Kendall CWC, Jenkins DJA. Fat versus carbohydrate in insulin resistance, obesity, diabetes and cardiovascular disease. Current Opinion in Clinical Nutrition Metabolic Care 2003; 6: 165-76.

41 Serra Majem L, Ribas Barba L, Armas Navarro A, Álvarez León EE, Sierra A. Equipo de investigación de ENCA. Consumo de Energía y Nutrientes y Riesgo de Ingesta Inadecuada. Encuesta Nutricional de Canarias. Archives of Latinoam Nutrition 2000; 50(Suppl 1): 7-22.

42 Soriguer F, Esteva I, Rojo-Martínez G, Ruiz de Adana MS, Dobarganes MC, García-Almeida JM, Tinahones F, Beltrán M, González-Romero S, Olveira G, Gómez-Zumaquero JM. Oleic acid from cooking oils is associated with lower insulin resistance in the general population (Pizarra study). European Journal of Endocrinology 2004; 150: 33-9.

43 Riccardi G, Giacco R, Rivellese AA. Dietary fat, insulin sensitivity and the metabolic syndrome. Clinical Nutrition 2004; 23(4): 447-56. 